\title{
Ombudsman, crítica, jornalismo e democracia
}

\author{
Juliana de Amorim ROSAS ${ }^{1}$
}

\begin{abstract}
Resumo:
Este artigo utiliza referências bibliográficas para refletir sobre o papel da autocrítica jornalística, em especial do ombudsman, na Teoria da Crítica de Imprensa - uma teoria normativa que tem como principal inspiração a teoria discursiva de Jürgen Habermas, desenvolvida pela autora americana Wendy Wyatt. O objetivo é tomar a teoria de Wyatt como base e discuti-la frente ao trabalho do ombudsman de imprensa. Propõe-se uma análise teórica do ombudsman pela luz desta teoria, uma vez que a autora faz suas críticas em relação ao papel do ombudsman e da autocrítica de imprensa em seu estudo. Apresenta-se a importância da atribuição do defensor do leitor dentro do jornal, do jornalismo e do seu papel normativo para a democracia, tendo uma função positiva dentro da teoria da crítica de imprensa.
\end{abstract}

Palavras-chave: Jornalismo. Ombudsman de imprensa. Democracia. Press Criticism.

\section{Ombudsman, criticism, journalism and democracy}

\begin{abstract}
:
This article uses bibliographic references to reflect on the role of journalistic self-criticism, especially the ombudsman, in the Press Criticism Theory - a normative theory which main inspiration is the discursive theory of Jürgen Habermas, developed by American author Wendy Wyatt. The goal is to take Wyatt's theory as a basis and discuss it through the press ombudsman's work. A theoretical analysis of the ombudsman is proposed, using this theory as a background, once the author herself criticizes the role of the ombudsman and press self-criticism in her study. It is presented the importance of the attribution of the public editor within the newspaper, to journalism itself and its normative role to democracy, having a positive role within the theory of press criticism.
\end{abstract}

Keywords: Journalism. Press ombudsman. Democracy. Press Criticism.

\section{Ombudsman, crítica, periodismo y democracia}

\section{Resumen:}

Este artículo utiliza referencias bibliográficas para reflexionar sobre el papel de la autocrítica periodística, especialmente del ombudsman, en la Teoría de la crítica de la prensa - una teoría normativa que tiene la teoría discursiva de Jürgen Habermas como su principal inspiración, desarrollada por la autora estadounidense Wendy Wyatt. El objetivo es tomar la teoría de Wyatt como base y discutirla a la luz del trabajo del defensor del lector. A la luz de esta teoría, se propone un análisis teórico del ombudsman, ya que la autora tiene sus críticas sobre esta ocupación periodística y sobre la autocrítica de la prensa en su teoria. Se presenta la importancia de atribuir al defensor del lector al periódico, al periodismo y su papel normativo para la democracia, que tiene una función positiva dentro de la teoría de la crítica de la prensa.

Palabras clave: Periodismo. Ombudsman. Democracia. Press Criticism.

\section{Introdução}

Em 2019, comemoramos 30 anos da estreia do primeiro ombudsman ${ }^{2}$ de imprensa no Brasil. Em setembro de 1989, a Folha de S. Paulo era o jornal pioneiro a

\footnotetext{
1 Doutoranda em Jornalismo pelo Programa de Pós-Graduação em Jornalismo da Universidade Federal de Santa Catarina.E-mail: rosasjuliana@yahoo.com.br
} 
implementar o cargo de defensor do leitor e apresentar o profissional que ouvia o público, realizava crítica interna diária do jornal para o qual trabalhava e possuía uma coluna semanal de crítica de imprensa.

Planejamos investigar mais a fundo a crítica e, especialmente, a autocrítica jornalística no Brasil. Uma das bases para o nosso questionamento e proposta de não somente entender, mas tentar obter uma base teórica que nos ajude a analisar a crítica é o trabalho da americana Wyatt (2007). Em Critical conversations - a theory of press criticism, a autora compõe um construto teórico a fim de elaborar uma teoria da crítica de imprensa - algo inédito até então.

Muitas foram as análises em torno da crítica de imprensa, ${ }^{3}$ porém, essas não formaram uma teoria, segundo a estudiosa. A teoria de Wyatt (2007) pretende-se normativa, como a própria afirma. Está baseada não no que a imprensa faz de fato, mas como deveria se comportar. Ela parte de diversos autores para construir uma base sólida da teoria. Nosso objetivo é tomar a teoria proposta por Wyatt (2007) e discuti-la frente ao trabalho do ombudsman de imprensa. Propomos, neste artigo, uma análise teórica do trabalho do ombudsman pela luz da teoria da crítica de imprensa lançada por essa autora. Ela própria tem suas críticas em relação ao ombudsman e à autocrítica de imprensa dentro da teoria exposta. Aqui, apresentamos a importância da atribuição do defensor do leitor dentro do jornal, do jornalismo e tendo um papel positivo dentro da teoria da crítica de imprensa.

Wyatt (2007, p. 18) afirma que jornalistas são notadamente hipersensíveis à crítica, embora reconheçam sua importância, bem como sabem que, historicamente, a autocrítica foi considerada uma alternativa à regulação. Autocrítica jornalística é algo que a autora apoia, porém, de acordo com sua proposta, não é o suficiente. É sobre essa questão que iremos nos debruçar ao longo deste artigo, especialmente pela própria pesquisadora enfatizar a relevância do público no desenvolvimento da crítica e no processo democrático. Dada a importância de participação do público e da autocrítica, vemos no ombudsman - profissional que faz autocrítica jornalística e atende ao público - um elemento relevante na crítica de imprensa.

Inspirada principalmente na teoria discursiva de Habermas, a teoria proposta por Wyatt conecta jornalismo e democracia, afirmando que o primeiro deve servir à última.

2 Seguindo o modelo adotado pelo jornal Folha de S. Paulo, neste artigo, usaremos as escritas ombudsman e ombudsmans, no singular e plural, respectivamente.

3 Ou press criticism, termo que a autora emprega e prefere a outros, como o media criticism. Aqui, adotaremos o primeiro. 
"A crítica é vista filosoficamente como um traço chave da democracia" (WYATT, 2007, p. 24, tradução nossa) e "crítica é a arma onde se fia a democracia" (WYATT, 2007, p. 25, tradução nossa), afirma.

\title{
Crítica, jornalismo e democracia
}

Na apresentação da edição do livro de Jürgen Habermas, Mudança estrutural da esfera pública, o professor Werle afirma:

\begin{abstract}
Nesta concepção clássica da vida pública, estabeleceu-se o núcleo histórico conceitual da ideia de democracia, entendida como prática de autodeterminação e autogoverno político de cidadãos livres e iguais que, no uso público da razão, discutem e deliberam sobre os temas e problemas da vida em comum (WERLE, 2014, p. 19).
\end{abstract}

Em seu percurso na construção de uma teoria normativa de crítica de imprensa, Wyatt (2007) afirma que esta deveria basear-se numa teoria normativa da imprensa e que o que falta talvez não seja a crítica em si, mas uma teoria desta, "um meio de orientar o esforço e promover o desenvolvimento de uma tradição sustentada, sistemática e intelectualmente sólida" (WYATT, 2007, p. 18, tradução nossa). Desde o início do seu livro, são citadas diversas vezes a união entre jornalismo, crítica e democracia, algo difícil de separar, segundo a autora.

Carey argumentou que "a democracia como forma de vida política é essencialmente uma teoria da crítica, e a crítica, adequadamente interpretada, é indispensável à ideia de liberdade"4. Portanto, a imprensa - considerada a instituição social mais importante que temos para alcançar comunicação democrática nesta vasta e complexa sociedade - deve ser submetida à mesma crítica a que submetemos outras instituições sociais (WYATT, 2007, p. 10, tradução nossa).

Wyatt (2007) concede importância ao público e à troca e circulação da crítica. Está aí nossa defesa do trabalho do ombudsman, pois este reside justamente em trocas com a audiência e, ao tornar pública sua crítica, impulsiona a circulação desta, propiciando outras trocas, com maiores públicos, bem como é um especialista em seu campo, dominando o objeto avaliado, como defendido anteriormente.

Idealmente, a democracia busca a participação de um público racional, interessado e informado - um público que, no seu sentido mais amplo, abrange todos os membros da sociedade. Além disso, para que o processo possa florescer, os membros do público precisam assumir a responsabilidade

${ }^{4}$ CAREY, James, Journalism and criticism: the case of an undeveloped profession. The Review of Politics, n. 36, p. 227-249, 1974. 
não apenas por suas próprias vidas, mas também pelo bem-estar da sociedade em geral. Contribuir para esse bem-estar - participar ativamente - exige que o público esteja bem informado sobre as questões sociais do dia. E como o processo democrático é dinâmico e as questões estão sempre mudando, o público precisa trabalhar continuamente para se manter informado (WYATT, 2007, p. 66, tradução nossa).

A autora pondera sobre as diferentes visões e ponderações acerca da democracia. "John Pauly ${ }^{5}$ comentou certa vez que o 'jornalismo quer desesperadamente entender a si mesmo como uma instituição democrática' " (WYATT, 2007, p. 70, tradução nossa), porém, como relata a autora, baseada nas tensões de opinião entre diferentes autores, não há consenso sobre o que isso quer dizer.

[...] é importante reconhecer a tensão entre a visão da democracia e sua prática atual. Mesmo com essa tensão, eu sugeriria que são as possibilidades da democracia que se tornam mais importantes quando se considera o papel ideal da imprensa - uma imprensa que opera não em uma democracia, mas em um processo democrático (WYATT, 2007, p. 70, tradução nossa).

\section{O ombudsman e a teoria da crítica de imprensa}

Mesmo com as ressalvas ao modelo de crítica produzida pelo ombudsman feitas pela autora americana, no trecho abaixo encontramos uma defesa do estilo de autocrítica que é realizada por este profissional especializado, que entende seu metiér.

Para fazer esse tipo de crítica com sucesso, Jensen argumentou que os críticos devem ter uma compreensão completa do objeto sob avaliação. Críticas não baseadas em entendimento, ele disse, não são críticas, mas um esforço equivocado que também pode desencaminhar os outros (WYATT, 2007, p. 43, tradução nossa).

Apesar de a autora ter suas observações ao tipo de trabalho do ombudsman, vemos que este faz o tipo de trabalho pelo qual Wyatt e autores nos quais ela se inspira defendem.

Portanto, para Carey, ${ }^{6}$ a crítica deve se concentrar nos métodos e convenções do jornalismo, convenções que foram apropriadas para o século XIX, mas que hoje tentam dar ordem a um mundo que não é mais ordenado ou lógico. [...] Os críticos devem, portanto, examinar os métodos pelos quais os jornalistas "definem e obtêm o que chamamos de notícias e as convenções pelas quais eles as entregam ao público". Esta crítica deve ser feita sistematicamente, continuamente e dentro das páginas da própria imprensa para o público que a consome. Para alcançar esse tipo de crítica, Carey argumentou, a imprensa deve usar seus recursos para promover uma comunidade crítica composta por aqueles leigos dentro do público "que estão

${ }_{5}^{5}$ PAULY, John. Journalism and the Sociology of public life - the idea of public journalism. Theodore L. Glasser (ed.). New York: The Guilford Press, 1999.

${ }^{6}$ CAREY, James W. Journalism and criticism: the case of an undeveloped profession. The Review of Politics, n. 36, p. 227-249, 1974. 
interessados em dar uma resposta crítica ao que veem e leem diariamente" (WYATT, 2007, p. 47, tradução nossa).

Carey menciona crítica sistemática, contínua e dentro das páginas dos jornais. Este é o trabalho do ombudsman. No Brasil e em muitos jornais no mundo, a presença do ombudsman nem sempre foi sistemática ou contínua, contudo, o exercício do seu trabalho diário assim o foi. Por isso, defendemos, não cabe apenas fazer crítica à figura do ombudsman, como se esta não tivesse funcionado ou não apresentado resultados significativos. A presença do ombudsman na imprensa brasileira foi inconstante, mas afirmar que a culpa é exclusiva do cargo é tirar uma conclusão apressada. A inconstância pode estar na incapacidade de receber e realizar autocrítica. E isso diz muito sobre o jornalismo como um todo, não somente sobre a função do ombudsman.

Baseada na teoria de Wyatt, a crítica de imprensa seria uma das maneiras de modificar a situação da imprensa que serviria a interesses escusos e particulares e alterar a visão de que esta seria um mero instrumento de propaganda, levando a seu papel normativo de vigilante da democracia. A autora apresenta considerações da teoria deliberativa elaborada por Habermas, seus defensores e críticos.

Ao ser, ele próprio, um canal de acesso, defendemos que o ombudsman seria uma peça importante para o processo, se não deliberativo, de circulação de crítica e informações - elementos relevantes na deliberação. A autora defende democracia enquanto crítica (WYATT, 2007, p. 96) e apresenta deliberação como seu sinônimo.

\footnotetext{
Na tentativa de argumentar sobre a necessidade da crítica em uma sociedade democrática, é importante deixar claro o que talvez já seja óbvio - o elo entre a deliberação e a crítica. Imediatamente, uma conexão se torna aparente na maneira como as duas palavras são definidas. [O dicionário] Oxford define crítica como oferecendo julgamento sobre algo com respeito a seus méritos ou falhas. Deliberação é a ação de pesar uma coisa na mente; consideração cuidadosa com vista à decisão; e a consideração e discussão das razões a favor e contra uma decisão. Eu gostaria de propor que a crítica racional é parte do processo deliberativo ou discursivo. Na ação de pesar uma coisa, considerá-la com cuidado e discutir as razões a favor e contra, os julgamentos a respeito dos méritos ou falhas da coisa são - e deveriam ser - oferecidos (WYATT, 2007, p. 88, colchetes e tradução nossos).
}

Não só a mídia de uma maneira geral promove informação e debate. $\mathrm{O}$ ombudsman igualmente faz parte desse processo, como canal de participação. Ele é um canal direto da audiência com o meio jornalístico. Mesmo atualmente, quando as pessoas deixam seus comentários em matérias on-line, o fato não quer dizer que aquilo irá gerar um feedback crítico. Como afirma Habermas (2014, p. 200, itálico do autor), 
“a opinião pública se forma pela disputa de argumentos em torno de uma questão, e não acriticamente, por meio do common sense".

Comentários encontrados na internet, mesmo em matérias jornalísticas, são frequentemente frutos de palavras impensadas, opiniões passionais, não refletidas de um usuário que, muitas vezes, discorda do conteúdo apresentado, porém, não por argumentos racionais, mas por bases ideológicas distintas. Como constatou Cervi (2013) e relatou a pesquisadora Fernanda Cavassana $^{7}$ (apud BEDINELLI, 2018), comentaristas na internet falam sozinhos e não buscam interação.

O ombudsman, no entanto, é uma implementação institucional. Ele existe para esse fim, a crítica. Uma vez que o modelo clássico de ombudsman consiste em analisar as matérias publicadas pela luz de reclamações dos leitores, pela sua própria capacidade crítica e de quem tem conhecimentos jornalísticos, este irá realizar uma crítica diária, que irá chegar aos editores e repórteres. Se esta irá promover mudanças factuais, é uma investigação à parte. Mas a circulação aconteceu. As informações chegaram ao destinatário. Na crítica semanal, o fluxo e trocas se tornam ainda maiores.

\footnotetext{
Um sistema de mídia dominado por poder e dinheiro pode ser a questão mais desafiadora que a teoria normativa da imprensa - particularmente a teoria discursiva - enfrenta; um ideal que se baseia no discurso racional-crítico pode facilmente entrar em conflito com as forças do poder e do dinheiro. Enfrentar esse conflito satisfatoriamente poderia exigir a reestruturação da imprensa, algo que Curran e outros recomendaram. Mas com base nas tendências atuais, tirar o sistema de mídia de notícias do mercado é incrivelmente improvável. Portanto, as influências do mercado, incluindo as crescentes influências da corporativização da mídia, conglomeração e globalização, devem ser reconhecidas (WYATT, 2007, p. 104, tradução nossa).
}

A teoria apresentada por Wyatt (2007), mesmo normativa, muitas vezes soa utópica. Há uma estruturação corporativa global bastante difícil de mudar. E, como mencionado, o ombudsman de imprensa já faz parte da estrutura. Não uma peça de manipulação dessa organização, pois, usando a defesa apresentada pela própria autora, elementos baseados em estratégias não funcionam nem na teoria discursiva habermasiana, nem na prática do ombudsman de imprensa, como descrevemos mais amplamente em outro momento (ROSAS, 2015). Antes de ser uma peça manipulável por outrem, pode-se ver o ombudsman como uma ferramenta neste sistema. Uma ferramenta que serve à crítica e ao público, pois, a depender do corpo empresarial, nota-

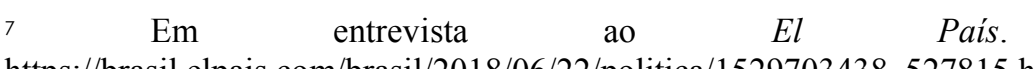
https://brasil.elpais.com/brasil/2018/06/22/politica/1529703438_527815.html
} 
se a não preferência por tal instrumento. $\mathrm{O}$ ombudsman pode ser o fórum para trocas e locus de crítica dentro do grande foro que é a imprensa. A própria autora traz:

\begin{abstract}
Conforme articulado pelos membros da Comissão Hutchins, a imprensa deveria servir como um fórum para a troca de comentários e críticas. De modo geral, espera-se que a imprensa não apenas divulgue informações, mas também contribua para a conversação pública "ajudando na expressão de diversos pontos de vista; dando acesso a muitas vozes na sociedade; [e] facilitar a participação dos cidadãos na vida social e política"8 (WYATT, 2007, p. 106, colchetes do original, tradução nossa).
\end{abstract}

Há um paradigma de arrogância e superioridade jornalísticas e aqui defende-se o ombudsman como solução institucional para tentar superar esse fato. Afinal, é seu dever ouvir a audiência e servir de elo na comunicação.

O paradigma dominante de disseminação de informações ajudou a criar o que Jay Rosen" chamou de "jornalismo fortaleza". Nessa perspectiva, a imprensa - em sua posição elevada como proprietária de informações - gasta seu tempo coletando e distribuindo fatos, mas na verdade não conversa com ninguém (WYATT, 2007, p. 107, tradução nossa).

O ombudsman pode ajudar na dissolução dessa "fortaleza" autoconstruída pelo jornalismo, justamente por ser um componente interior, cujo principal trabalho é criticar a imprensa de dentro para fora, porém, com um olhar exterior, do próprio profissional e dos leitores que o escrevem. Uma das características da imprensa que perpetuam seus problemas é que, como menciona a própria Wyatt (2007, p.107, tradução nossa), "a imprensa se apresenta como serviço público mas não sabe o que isso significa. $O$ objetivo é definido em termos culturais, políticos, mas frequentemente é o de dar lucro enquanto negócio". Mais adiante, afirma que a mídia se justifica em nome do público, mas este é apenas consumidor. "O jornalismo perdeu a conexão crítica em parte por problemas criados pelo jornalismo" (WYATT, 2007, p. 108, tradução nossa). Daí, inquirimos, por que não a solução surgir também no/pelo jornalismo? Como o ombudsman, por exemplo?

O propósito final da imprensa é definido pelas exigências de uma democracia deliberativa, particularmente uma democracia que deve operar dentro dos limites impostos por uma sociedade complexa e descentralizada. Esse tipo de sociedade precisa de um fórum para oferecer aos cidadãos oportunidades de discursos. Novamente, é impossível imaginar um público discursivo em grande escala sem uma imprensa que forneça uma maneira de conectar os membros de um público desconectado uns com os outros. O propósito da

\footnotetext{
${ }^{8}$ MCQUAIL, Denis. Normative theory of media and society. London: Sage, 2000.

9 ROSEN, Jay. The action of the idea: public journalism in built form in the Idea of public journalism.

Theodore L. Glasser (ed.). New York: Guilford Press, 1999.
} 


\begin{abstract}
imprensa é legitimado através do próprio propósito da democracia deliberativa - entendimento mútuo. Para alcançar a compreensão mútua, os participantes devem ter acesso ao discurso da formação de opinião intersubjetiva. A compreensão mútua é inatingível se todos os afetados não tiverem a oportunidade de participar. Portanto, a imprensa, ao servir seu próprio propósito como uma esfera pública comunicativa, também contribui para a realização do propósito da sociedade (WYATT, 2007, p. 110, tradução nossa).
\end{abstract}

Como menciona Habermas (2014, p. 127-128), segundo uma ordem de 1727 do gabinete prussiano, essa instituição (as agências de anúncio e informações) deveria ser um meio de "servir ao público" e "facilitar a circulação". Ou seja, havia uma função normativa da imprensa (ainda que nos seus primórdios e não assim denominada) de prestação de serviço público.

Wyatt acrescenta que, além do mencionado acima, a crítica deve incentivar a participação, pois a noção de jornalismo como uma esfera pública deve depender não apenas da imprensa, mas também do público. "Assim como o sucesso da democracia deliberativa depende da participação dos cidadãos, o processo de deliberação pública e formação de opinião que a imprensa facilita também exige que o público opte pelo processo" (WYATT, 2007, p. 111, tradução nossa). Verificamos que esse papel pertence também ao ombudsman - ele clama que o público opte por participar. A essa ideia acrescenta-se o que a autora afirma mais à frente: "Esfera pública é um fórum dialógico. Jornalismo deveria não somente informar o cidadão, mas conectá-lo" (WYATT, 2007, p. 114, tradução nossa). Mais uma vez, verificamos que o ombudsman serviria para conectar o cidadão à imprensa e, por meio desta, à crítica à própria imprensa. Wyatt afirma que, antes da penny press, o objetivo da imprensa era a conexão (discourse), mas que, com o tempo, esse objetivo se perdeu (WYATT, 2007).

Os jornalistas são apenas parte das conversas de nossa cultura: um parceiro como o resto de nós - nem mais nem menos. Este é um papel humilde para o jornalismo - ou assim parece à primeira vista - mas na verdade o que precisamos é de um jornalismo humilde. [...] O jornalismo não pode dizer a verdade porque ninguém pode dizer a verdade. Tudo o que o jornalismo pode fazer é presidir a conversa da nossa cultura; estimulá-lo e organizá-lo, mantêlo em movimento e deixar um registro dele para que outras conversas - arte, ciência, religião - possam ter algo de que possam se alimentar. O público começará a despertar quando for abordado como um parceiro de conversação e for incentivado a participar da palestra em vez de ficar passivamente como espectador ante uma discussão conduzida pelo jornalismo $\left(\mathrm{CAREY}^{10}\right.$ apud WYATT, 2007, p. 115, tradução nossa).

10 CAREY, James. A critical reader. Edition: NED - New edition, 1997. 
Indaga-se por que esse parceiro de conversação não pode ser o ombudsman. Por que essa função não poderia estimular conversas e trocas? Como afirma Habermas (2014, p. 80), "os discursos não dominam. Eles produzem um efeito comunicativo que não substitui o poder administrativo, mas pode apenas influenciá-lo". O ombudsman pode não mudar o jornal, mas pode gerar um processo de trocas entre público e redação e discussões no espaço público.

Para Wyatt (2007), o problema é que o ombudsman espera que a audiência venha até ele, o que geraria um processo mais reativo que ativo. Deve-se esclarecer que, no modelo clássico de ombudsman, tornado conhecido nos Estados Unidos, este não é um mero receptáculo de reclamações ou serviço de atendimento ao consumidor. Glasser (2002, p. 219) afirmou que segundo um levantamento do ano 1994, cerca de dois terços dos ombudsmans americanos escreviam colunas públicas.

Todavia, com algumas exceções notáveis, essas crônicas preenchem uma função de relações públicas para os jornais e não asseguram um aporte regular de comentário crítico sobre a imprensa local [...]. A leitura de cerca de 800 crônicas escritas por ombudsmen de uma ponta a outra do país mostra que a desculpa é mais corrente do que a crítica incisiva. Frequentemente, para explicar, invocam-se as difíceis condições de trabalho dos jornalistas (GLASSER, 2002, p. 219).

Parte desse relato surpreende, uma vez que é no jornalismo americano onde surge o termo "watchdog journalism", um jornalismo que se pretende vigilante. Cabe lembrar: o primeiro ombudsman do ocidente surgiu nos Estados Unidos em 1967, no jornal Louisville Courier Journal, do estado americano de Kentucky. Tomando a análise feita por Glasser (2002), é compreensível a visão de Wyatt sobre a autocrítica encontrada em jornais. Um trecho retirado de Ferrucci (2018), no entanto, ajuda a minimizar e compreender melhor a associação entre ombudsman e relações públicas.

No entanto, enquanto o ombudsman atua como crítico de mídia e representa as pessoas ao discutir publicamente o desempenho jornalístico, os estudiosos descobriram que eles também atuam como executivos de relações públicas de fato para as redações. Ettema e Glasser $(1987)^{11}$ descobriram que a "parte mais importante do trabalho" era "dar aos leitores a sensação de que o jornal se preocupa com eles” (p. 7), que é, essencialmente, uma função de relações públicas (FERRUCCI, 2018, p. 4, tradução nossa).

Em referências brasileiras - bibliográficas e textos jornalísticos, especialmente é comum encontrar duras críticas à maneira como surgiu a função do ombudsman - o

11 ETTEMA, J. S; GLASSER, T. L. Public accountability or public relations? Newspaper ombudsmen define their role. Journalism \& Mass Communication Quarterly, n. 64, p. 3-12, 1987. 
profissional jornalista, contratado para criticar seu próprio jornal, possuindo no veículo uma coluna pública semanal. As críticas variavam de jogada de marketing, bedel de jornal, a relações públicas do veículo. Porém, baseados especialmente em pesquisa anterior (ROSAS, 2015), verificamos que o trabalho em si do ombudsman é sério e crítico, permeado, não obstante, por questões que fogem ao seu controle, como relações do jornal com o governo, partidos políticos ou anunciantes; ou seja, a problemas jornalísticos e não jornalísticos diversos, não somente da instituição ombudsman.

Aqui focamos na importância da autocrítica do jornalismo e do trabalho do ombudsman frente às apreciações expostas por Wyatt (2007) na construção de sua teoria da crítica de imprensa. Apresentamos, contudo, um exemplo de como em colunas analisadas em pesquisa anterior (ROSAS, 2015) encontram-se ombudsmans que publicavam duras críticas a seu próprio jornal em coluna pública, sem apresentar desculpas com relação ao trabalho da redação.

Ao tratar assuntos polêmicos do Governo do Estado, o CORREIO deve levar sempre em conta dois aspectos que ameaçam sua reputação de independência: 1 - que num passado recente foi exageradamente governista e ganhou uma reputação da qual a muito custo vem se livrando; 2 - que o outro parâmetro dado hoje aos leitores pessoenses, de jornal independente é $\mathbf{O}$ Norte, que sempre descamba para a oposição panfletária quando o assunto envolve o Governo do Estado, mas que, num contexto de aparente unanimidade da imprensa pró-Cunha Lima, pode conquistar a simpatia do público insatisfeito com a situação estadual (CR) [grifos do original] (OMBUDSMAN, 1991, p. 13).

\section{Do fato à norma}

Após apresentar e ponderar sobre uma revisão sistemática de crítica e evidenciar visões que sustentam a teoria de imprensa - base, segundo a própria autora, para sua sugerida teoria da crítica de imprensa - Wyatt afirma que torna-se útil mudar do fato para a norma, "da evidência empírica do que a imprensa é e faz em nossa democracia liberal pós-industrial para uma discussão filosófica do que a imprensa deveria ser e fazer em uma democracia construída em um modelo discursivo" (WYATT, 2007, p. 109, tradução nossa). Ao expor o propósito teleológico da imprensa, a autora afirma que "o paradigma muda de transmissão para troca, de monólogo para diálogo, de persuasão para compreensão mútua" (WYATT, 2007, p. 110, tradução nossa). 
instituindo um procedimento que ajuda a alcançar a meta democrática deliberativa de entendimento mútuo. Aqui fica claro o quão inextricavelmente ligados estão a democracia e a imprensa (WYATT, 2007, p. 111, colchetes do original, tradução nossa).

A partir daí, visualiza-se uma compreensão maior do propósito normativo proposto por Wyatt. Segundo ela, o jornalismo e o público deveriam se encontrar no meio do caminho, unir-se nesse objetivo em comum de, por meio do jornalismo, melhorar a democracia. O jornalismo atuaria como movimento social de mudança e a crítica seria um caminho para chegar neste intuito.

\begin{abstract}
Assim como a teoria discursiva de democracia de Habermas é uma teoria normativa, assim são as ideias para a imprensa baseadas nela. Democracia deliberativa é um projeto que deve ser levado adiante, e mudança em uma instituição, uma prática, um movimento pode efetuar mudanças em todo o projeto. Mas onde esta mudança começa? Em seu trabalho, Habermas se limita a argumentos normativos, mas nota que sua teoria depende de uma cultura política e de um público que se encontra no meio do caminho. Uma mudança na imprensa - em uma instituição - certamente poderia ajudar a facilitar esse encontro. [...] Mas onde começa a mudança no jornalismo? Com essa pergunta, volto ao foco deste livro. Servindo como uma espécie de movimento social, a crítica da imprensa pode atuar como um dos veículos mais encorajadores para a mudança. Seguindo os princípios de uma teoria do discurso da democracia, a crítica pode desafiar publicamente as normas culturais e os códigos de imprensa amplamente compartilhados e criar novos entendimentos, que podem então alterar as condições da imprensa e, em última análise, as condições da sociedade. Esta não é uma tarefa fácil (WYATT, 2007, p. 126, tradução nossa).
\end{abstract}

Verifica-se que mesmo os caminhos dados pela autora são normativos. O propósito final pode ser normativo. Se se adota a democracia como modo de vida político, deve-se trabalhar para mantê-la e melhorá-la. No entanto, como a própria autora reconhece, há inúmeros obstáculos pelo percurso, incluindo vontade e participação.

A esfera pública não existe essencialmente para satisfazer os nossos ideais de justiça, nem em virtude da soberania popular nem para o bem da comunidade política. Esferas públicas que satisfazem tais requisitos devem ser construídas, devem ser acompanhadas por uma cultura política favorável, em que valores democráticos sejam compartilhados extensa e intensamente, devem ser guardadas e reforçadas. Sistemas de recompensas e de constrangimentos precisam ser construídos para sua salvaguarda, instituições precisam ser desenhadas para a sua reprodução, leis precisam ser produzidas para que o Estado funcione como garantidor da sua existência, cidadãos precisarão ser convencidos da sua imprescindibilidade. Uma esfera pública pró-democrática é uma tarefa, não uma consequência que se possa extrair normativamente do seu conceito (GOMES; MAIA, 2008, p. 111-112). 
Ou seja, democracia é construção. Se o meio é a crítica, a responsabilidade inicial está com a imprensa e a autocrítica é um começo e uma direção. Como é referido abaixo, é responsabilidade dos críticos gerar transformações, e, assim, acepções públicas a respeito da imprensa. As ouvidorias podem ter surgido por demanda, contudo, seu aparecimento igualmente gerou mais participação, uma vez que o público soube da existência de um canal de troca e reclamação. Assim é o ombudsman. Ele pode gerar transformações dentro do próprio veículo, ao mostrar o que os afazeres diários podem esconder, e mostra ao leitor que, quando desejar, haverá uma via para manifestação.

Wyatt (2007) aponta que um dos propósitos da crítica é fazer com que os cidadãos se engajem e participem. Refletimos, então, que a crítica não deve vir somente do próprio público. E como é mencionado pela autora, não deve provir somente de acadêmicos e especialistas. Não podendo vir somente da audiência, não deveria manifestar-se exclusivamente nas mídias sociais, uma vez que, a princípio, o crítico não estaria interagindo nestas.

Para Habermas (2014, p. 269, itálico do original), “a esfera pública não se realiza unicamente na república dos instruídos, mas sim no uso público da razão de todos que nela se entendem. No entanto, estes últimos precisam sair dos limites de sua esfera privada como se fossem instruídos". Algo certamente difícil de encontrar unicamente em debates on-line.

A comunicação, de modo geral, parece nunca ter ganhado status de esfera pública no Brasil. Haja vista que mesmo com governos progressistas não conseguimos avançar em regulamentações e legislações na área, atualmente, o jornalismo sofre sérios ataques da população e dos próprios poderes. Ter o jornalismo status de esfera pública seria uma condição normativa para avançar. Novamente é referida a troca entre crítica e público e mais uma vez visualizamos o papel do ombudsman. É assinalado (WYATT, 2007) que os críticos servem para manter a imprensa conectada a seu público. O ombudsman, ao transmitir ao veículo o que pensam seus leitores, está mantendo a conexão.

Os críticos que adotam um modelo discursivo da imprensa devem ganhar influência suficiente para convencer tanto a imprensa quanto o público de que essa visão normativa merece seu endosso. Uma vez que o modelo discursivo tenha sido aceito, a transformação da imprensa pode começar. Baseada em parte na opinião dos críticos, a imprensa pode alcançar um "status" genuíno da esfera pública. Mas, como uma democracia discursiva, 
uma imprensa discursiva é um projeto em andamento e a imprensa está em contínua transformação. O papel dos críticos como cão de guarda [original: watchdog], portanto, ajuda a garantir que, mais do que qualquer coisa, a imprensa continue a responder à mudança do terreno em que se encontra, que não caia em estagnação. Importante notar aqui é que um modelo discursivo depende não apenas da imprensa, mas também do público, então a crítica da imprensa também é necessariamente crítica do público. Além de avaliar até que ponto a imprensa está cumprindo suas responsabilidades, os críticos de imprensa também devem avaliar o público em seu papel de participante (WYATT, 2007, p. 135, colchetes e tradução nossos).

\section{Considerações finais}

Apresentamos aqui uma defesa inicial do trabalho do ombudsman dentro de um jornal, sua importância para o jornalismo e, em especial, para a crítica de imprensa. Vimos que a principal teórica no qual a reflexão é baseada, Wendy Watt, autora de uma teoria da crítica de imprensa, possui suas ressalvas com relação a este ofício. Talvez Wyatt permanecesse com a visão das críticas do trabalho do ombudsman americano de alguns períodos, em especial o abordado por Glasser (2002). Há que se frisar, ainda assim, o trabalho público de crítica à imprensa realizado pelo ombudsman, ou seja o press criticism tão caro à autora. Muitos autores concordam que a crítica é uma forma de accountability e o ombudsman seria um dos modos de fazer tal prestação de contas.

Quando pensamos no accountability da mídia, devemos entender que, geralmente, esses objetivos são alcançados através de uma mistura de várias práticas com um entendimento implícito de que, se o jornalismo não se responsabilizar, perderá credibilidade e sua capacidade de promover a democracia, objetivo normativo do jornalismo (McQuail, 2003; Plaisance, $2000)^{12}$. Uma das formas mais visíveis e tangíveis pelas quais o jornalismo se responsabiliza é através do emprego de ombudsmen ou editores públicos (Mogavero, 1982 $2^{13}$ ) (FERRUCCI, 2018, p. 3, tradução nossa).

Em sua proposta teórica, Wyatt apresenta explicações compreensíveis sobre seu ponto de vista de que a autocrítica jornalística não é suficiente no procedimento. Nossa perspectiva, entretanto, é que esta ainda é uma função do ombudsman e que a autocrítica é não somente um primeiro passo, mas uma etapa importante, que deve ser constante em todo o processo da crítica.

\footnotetext{
12 MCQUAIL, D. Media accountability and freedom of publication. New York, NY: Oxford University Press, 2003.

PLAISANCE, P. L. The concept of media accountability reconsidered. Journal of Mass Media Ethics, n. 15 , p. $257-268,2000$.

13 MOGAVERO, D. T. The American press ombudsman. Journalism \& Mass Communication Quarterly, n. 59, p. 548-580, 1982.
} 
Iniciar o processo de crítica, reconhece a autora, não é um trabalho fácil, pois a imprensa é uma instituição resistente à mudança e lhe falta motivação para tal (WYATT, 2007). Contudo, ela mesma admite que uma tradição de crítica não pode se desenvolver sem a imprensa. Cabe a esta institucionalizar os procedimentos.

Neste artigo, defendemos que a autocrítica é um primeiro, importante e grande passo. Mas não somente. Ela não deve ser apenas um pontapé. Deve continuar e perfazer todo o processo. A ouvidoria é uma instituição que já faz parte da democracia e o ombudsman, por sua vez, é outra instituição dentro da instituição jornalística. Se Habermas (2003) utilizou algumas metáforas para descrever seu conceito de esfera pública, como a dos sensores sociais, esta seria uma ampla rede de radares e sensores localizados no interior da sociedade, sensíveis a ponto de perceber e identificar os problemas desta. O ombudsman pode ser um sensor social, uma espécie de radar e também concha acústica para a audiência. Assim como as ouvidorias existem para ouvir e fiscalizar outros poderes, os ombudsmans podem ser os cães de guarda dos cães de guarda.

\section{Referências}

BEDINELLI, Talita. "Comentaristas de matérias políticas no Facebook falam sozinhos". Pesquisadora Fernanda Cavassana de Carvalho fala sobre análise de 600.000 comentários feitos em matérias referentes às eleições de 2014. EI País, editoria Brasil, 03 jul. 2018. Disponível em:

https://brasil.elpais.com/brasil/2018/06/22/politica/1529703438_527815.html. Acesso em: 04 jul. 2019.

CERVI, Emerson Urizzi. Como os webleitores do "Portal Estadão" comentaram a eleição de Dilma Rousseff em 2010: uma discussão sobre os participantes do debate público em campanhas eleitorais nos novos meios de comunicação. Explanans, Zinacantepec, México, v. 2, n. 1, p. 75-99, enero-junio 2013.

FERRUCCI, Patrick. The end of ombudsmen? 21st-Century Journalism and Reader Representatives. Journalism \& Mass Communication Quarterly, p. 1-20, 2018.

GLASSER, Theodore L. O ombudsman de imprensa nos Estados Unidos. In: BERTRAND, Claude-Jean. O arsenal da democracia. Bauru: EDUSC, p. 213-221, 2002.

GOMES, Wilson; MAIA, Rousiley. Comunicação e democracia: problemas e perspectiva. São Paulo: Paulus, 2008.

HABERMAS, Jürgen. Mudança estrutural da esfera pública: investigações quanto a uma categoria da sociedade burguesa. São Paulo: UNESP, 2014. 
HABERMAS, Jürgen. Direito e democracia: entre facticidade e validade. 2. ed. Rio de Janeiro: Tempo Brasileiro, 2003.

OMBUDSMAN. Correio da Paraíba, p. 13, 04 ago. 1991.

ROSAS, Juliana de Amorim. Os cães ladram, a caravana passa e apenas ao leitor se deve reverência: o pioneirismo regional do ombudsman paraibano entre críticas, estratégias e conflito de ethos. 2015. Dissertação (Mestrado em Comunicação) - Setor de Artes, Comunicação e Design, Universidade Federal do Paraná, Curitiba, 2015.

WERLE, Denilson Luís. Apresentação à edição brasileira. In: HABERMAS, Jürgen. Mudança estrutural da esfera pública: investigações quanto a uma categoria da sociedade burguesa. São Paulo: UNESP, 2014. p. 19-34.

WYATT, Wendy. Critical conversations - a theory of press criticism. Broadway: Hampton Press, 2007.

Submetido em: 01.10.2019

Aprovado em: 26.01.2020 